\title{
Long term survival in 200 patients with advanced stage of colorectal carcinoma and diabetes mellitus - a single institution experience
}

\author{
Nikola Besic ${ }^{1}$, Milena Kerin Povsic ${ }^{2}$ \\ ${ }^{1}$ Department of Surgical Oncology, Institute of Oncology Ljubljana, Slovenia \\ ${ }^{2}$ Department of Anesthesiology and Intensive Care, Institute of Oncology Ljubljana, Slovenia
}

Radiol Oncol 2019; 53(2): 238-244.

Received 31 January 2019

Accepted 7 April 2019

Correspondence to: Milena Kerin Povšič, M.D. Ph.D., Department of Anesthesiology and Intensive Care, Institute of Oncology Ljubljana, Zaloška 2, SI-1000 Ljubljana, Slovenia. Phone: +386 15879 916; Fax: +386 15879 400; E-mail: mkerin@onko-i.si

Disclosure: No potential conflicts of interest were disclosed.

\begin{abstract}
Background. Diabetes mellitus (DM) and DM related comorbidities may initiate difficulties during cancer specific treatment and may have an impact on cancer management and outcome. The aim of our study was to find out if DM in patients with advanced colorectal carcinoma (CRC) is associated with cancer-specific or overall survival.

Patients and methods. This study included 200 consecutive patients ( 131 males, 69 females, mean age 63 years) with elective CRC surgery at the Institute of Oncology Ljubljana and DM was found in 39 (19.5\%) of them. Even $64 \%$ of patients had Stage 3 or 4 disease, so neo-adjuvant chemotherapy (CTX) and/or radiotherapy (RT) were carried out in $59 \%$ of cases. Data about gender, age, body mass index, presence of DM, American Society of Anesthesiologists (ASA) physical status score, stage of disease and postoperative complications were collected prospectively. Cancerspecific survival and overall survival were compared by log-rank test.

Results. Patients with DM had a higher ASA score, BMI, the illness marker, rate of massive bleeding, blood transfusion and longer hospital stay than those without DM. The mean follow-up period was 4.75 years. All causes mortality in patients with DM and without DM was $23 \%$ and $27 \%$, respectively. Three-year cancer-specific survival in patients with DM and without DM was $85 \%$ and $89 \%$, respectively $(p=0.68)$. Three-year overall survival in patients with DM and without DM was $82 \%$ and $84 \%$, respectively $(p=0.63)$.

Conclusions. The presence of DM was not associated with tumor stage, disease-specific survival or overall survival in patients with advanced CRC.
\end{abstract}

Key words: colorectal carcinoma, diabetes mellitus, surgery, survival

\section{Introduction}

Diabetes mellitus (DM) is known to be an independent risk factor for the development of colorectal cancer (CRC). ${ }^{1,2}$ The risk of colorectal cancer was estimated to be $27 \%$ higher in patients with type 2 DM than in non-diabetic controls. ${ }^{3}$ However, it is unclear if the presence of diabetes in patients with $\mathrm{CRC}$ is associated with the cancer-specific survival of patients after cancer diagnosis. ${ }^{4}$ Some authors found that patients with CRC and diabetes are at greater risk of all-cause and cancer-specific mortality and have worse disease-free survival compared to those without diabetes. ${ }^{5}$ But other authors found that the presence of DM in patients with CRC was not associated with worse cancer-specific survival. ${ }^{4}$

Diabetes mellitus and DM related comorbidities may initiate difficulties during cancer specific 
treatment and may have an impact on cancer management and outcome. Colorectal cancer surgery is often followed by postoperative complications which may impact survival. The aim of our study was to find out if DM in patients with advanced colorectal carcinoma is associated with cancer-specific or overall survival.

\section{Patients and methods}

This study included 200 consecutive patients (131 males, 69 females, mean age 63 years) with elective colorectal cancer surgery at the Institute of Oncology Ljubljana from September 2010 to March 2013. In 14 patients, curative resection of liver metastases was carried out during the same anesthesia. In all the patients, a laparotomy was performed. The exclusion criteria were preoperative infection, preoperative ileus and palliative surgical procedure. ${ }^{6,7}$ All 200 patients were prospectively included in the study about the usefulness of biomarker index CD64 for neutrophils (iCD64n) for early detection of postoperative infection. ${ }^{6,7}$ The study protocol was approved by the Republic of Slovenia National Medical Ethics Committee. Approval and written consent for the retrospective study of the long-term outcome of the patients was obtained from the Protocol Review Board (MZ 0120-28/2016-2, ERID-KSOPKR/20), and the Ethics Committee of the Institute of Oncology (ERIDKSOPKR/77, OIRIKE 0049).

Rectum, colon and both of them were affected by cancer in $68 \%, 30 \%$ and $2 \%$ of cases, respectively. Stage of tumor was evaluated clinically according to the nuclear magnetic resonance (NMR) investigation before the beginning of the treatment. The TNM classification was used for staging of colorectal cancer disease. ${ }^{8}$ Even $64 \%$ of patients had Stage 3 or 4 disease, so neo-adjuvant chemotherapy (CTX) and/or radiotherapy (RT) were carried out in $59 \%$ of cases. CTX and/or RT were carried out and finished six to eight weeks before surgery, as reported by Golo et al..$^{9}$ Each patient was assessed preoperatively according to the American Society of Anesthesiologists (ASA) physical status classification, which accurately predicts morbidity and mortality. ${ }^{10}$ Bioelectric impedance analysis (BIA) measurement was performed on the day before the surgery using a portable bioelectrical impedance analyzer BodyStat QuadScan 4000 (Douglas, Great Britain), as already described by Kerin-Povsic et al. ${ }^{7}$ Phase angle is the ratio between the reactance and resistance. ${ }^{11}$ The illness marker is the ratio between the impedance measurement at $200 \mathrm{kHz}$ and $5 \mathrm{kHz}$. A ratio closer to 1.00 indicates poor cellular health or extreme fluid overload.

DM was found in 39 (19.5\%) of patients: 19 were treated only with metformin, 5 only with insulin, while 15 were treated with two or three different oral antidiabetics.

Data about gender, age, body mass index, presence of DM, American Society of Anesthesiologists (ASA) physical status score, stage of disease and postoperative complications were collected prospectively.

All patients had a follow-up at the Institute of Oncology Ljubljana. Cancer-specific survival was defined as the period from the first day of primary treatment (surgery, CTX or RT) to death from colorectal cancer, or the last follow-up. Overall survival was defined as the period from the first day of primary treatment (surgery, CTX or RT) to death from any cause, or the last follow-up. Disease-free survival was defined as the period from the first day of primary treatment to the radiologic or morphologic diagnosis of recurrence, or the last follow-up. The median duration of follow-up was 5.1 years (range $0.2-10.5$ years).

The association between categorical variables was tested by the Pearson chi-square test or Fisher's exact test, as appropriate. Univariate analysis was used to identify factors associated with cancer-specific and overall survival. Cancer-specific survival and overall survival were compared by log-rank test. All comparisons were two-sided, and a p-value of $<0.05$ was considered statistically significant. Survival curves were calculated according to the Kaplan-Meier method. Statistical analyses were performed using the SPSS software (IBM Corp., version 22.0 Armonk, NY).

\section{Results}

Data about patient's characteristics, tumor, treatment and outcome are presented in Table 1 . The mean age of patients with and without DM was 65 and 62 years, respectively. There was no statistically significant difference in the age of patients with and without DM $(p=0.13)$. However, patients with DM had a higher ASA score $(p=0.0001)$ and BMI $(p=0.003)$ than those without DM. Furthermore, before surgical procedure, the illness marker was higher in patients with DM in comparison to those without DM $(p=0.02)$. However, higher disease stages were not more common in patients with DM in comparison to those without DM. Stage 3 or 4 
TABLE 1. Patient's characteristics, tumor, treatment and outcome

\begin{tabular}{|c|c|c|c|c|}
\hline Characteristic & & $\begin{array}{l}\text { Without diabetes } \\
\text { mellitus } \\
(\mathrm{N}=161)\end{array}$ & $\begin{array}{l}\text { With diabetes } \\
\text { mellitus } \\
(\mathrm{N}=39)\end{array}$ & p-value \\
\hline Age (years) - mean & & 62.18 (SD \pm 11.8$)$ & $65.26(S D \pm 8.9)$ & 0.13 \\
\hline Gender & $\begin{array}{l}\text { Male } \\
\text { Female }\end{array}$ & $\begin{array}{l}106 \\
55\end{array}$ & $\begin{array}{l}25 \\
14\end{array}$ & 0.84 \\
\hline $\begin{array}{l}\text { American Society of } \\
\text { Anesthesiologists physical status } \\
\text { classification score }\end{array}$ & $\begin{array}{l}\text { I } \\
\text { II } \\
\text { III } \\
\text { IV }\end{array}$ & $\begin{array}{l}14 \\
95 \\
47 \\
5\end{array}$ & $\begin{array}{l}0 \\
10 \\
29 \\
0\end{array}$ & 0.0001 \\
\hline Body mass index $\left(\mathrm{kg} / \mathrm{m}^{2}\right)$ - mean & & $26.83(S D \pm 4.20)$ & $29.06(S D \pm 4.1)$ & 0.003 \\
\hline Treatment of diabetes & $\begin{array}{l}\text { Insulin only } \\
\text { Metformin only } \\
2 \text { or } 3 \text { oral antidiabetics }\end{array}$ & $\begin{array}{l}- \\
-\end{array}$ & $\begin{array}{l}5 \\
19 \\
15\end{array}$ & - \\
\hline Phase angle $\left({ }^{\circ}\right)$ - mean & & $5.47(S D \pm 1.0)$ & $5.16(S D \pm 0.9)$ & 0.11 \\
\hline Illness marker - mean & & $0.807(S D \pm 0.036)$ & $0.825(S D \pm 0.049)$ & 0.02 \\
\hline Dry lean body mass $(\mathrm{kg})$ - mean & & $12.97(S D \pm 4.5)$ & $12.65(S D \pm 4.6)$ & 0.72 \\
\hline Tumor site & $\begin{array}{l}\text { Rectum } \\
\text { Colon } \\
\text { Rectum + Colon }\end{array}$ & $\begin{array}{l}113 \\
47 \\
1\end{array}$ & $\begin{array}{l}24 \\
13 \\
2\end{array}$ & 0.09 \\
\hline Stage TNM & $\begin{array}{l}0 \\
\text { I } \\
\text { II } \\
\text { III } \\
\text { IV }\end{array}$ & $\begin{array}{l}3 \\
21 \\
33 \\
91 \\
13\end{array}$ & $\begin{array}{l}0 \\
6 \\
9 \\
18 \\
6\end{array}$ & 0.50 \\
\hline Preoperative radiotherapy & $\begin{array}{l}\text { No } \\
\text { Yes }\end{array}$ & $\begin{array}{l}67 \\
94\end{array}$ & $\begin{array}{l}18 \\
21\end{array}$ & 0.61 \\
\hline Preoperative chemotherapy & $\begin{array}{l}\text { No } \\
\text { Yes }\end{array}$ & $\begin{array}{l}90 \\
71\end{array}$ & $\begin{array}{l}22 \\
17\end{array}$ & 0.95 \\
\hline Surgical procedure & $\begin{array}{l}\text { Low anterior resection } \\
\text { Miles + Hartman } \\
\text { Colon resection }\end{array}$ & $\begin{array}{l}73 \\
38 \\
50\end{array}$ & $\begin{array}{l}13 \\
12 \\
14\end{array}$ & 0.38 \\
\hline $\begin{array}{l}\text { Synchronous resection of liver } \\
\text { metastases }\end{array}$ & $\begin{array}{l}\text { No } \\
\text { Yes }\end{array}$ & $\begin{array}{l}151 \\
10\end{array}$ & $\begin{array}{l}35 \\
4\end{array}$ & 0.48 \\
\hline Duration of surgery (min) - mean & & $175(S D \pm 66)$ & $199(S D \pm 64)$ & 0.034 \\
\hline Loss of blood $(\mathrm{mL})$-mean & & $584(S D \pm 497)$ & $813(S D \pm 812)$ & 0.027 \\
\hline $\begin{array}{l}\text { Postoperative transfusion of } \\
\text { packed red blood cells (mL) } \\
\text {-mean }\end{array}$ & & $351(S D \pm 516)$ & $603(S D \pm 665)$ & 0.011 \\
\hline Postoperative infection (any site) & $\begin{array}{l}\text { No } \\
\text { Yes }\end{array}$ & $\begin{array}{l}110 \\
51\end{array}$ & $\begin{array}{l}22 \\
17\end{array}$ & 0.16 \\
\hline Re-operation & $\begin{array}{l}\text { No } \\
\text { Yes }\end{array}$ & $\begin{array}{l}153 \\
8\end{array}$ & $\begin{array}{l}35 \\
4\end{array}$ & 0.21 \\
\hline Hospital stay (days) -mean & & $14.4(S D \pm 7.6)$ & 19.9 (SD \pm 10.6$)$ & 0.028 \\
\hline Recurrence $(N=181)$ & $\begin{array}{l}\text { No } \\
\text { Locoregional } \\
\text { Distant } \\
\text { Locoregional + distant }\end{array}$ & $\begin{array}{l}111 \\
4 \\
26 \\
7\end{array}$ & $\begin{array}{l}28 \\
1 \\
3 \\
1\end{array}$ & 0.63 \\
\hline Outcome & $\begin{array}{l}\text { Alive } \\
\text { Dead of disease } \\
\text { Dead of other causes } \\
\text { Dead - Unknown cause }\end{array}$ & $\begin{array}{l}117 \\
34 \\
9 \\
1\end{array}$ & $\begin{array}{l}30 \\
7 \\
1 \\
1\end{array}$ & 0.74 \\
\hline
\end{tabular}

disease was found in patients with DM and without DM in $62 \%$ and $65 \%$, respectively $(\mathrm{p}=0.72)$. So, also the proportion of patients treated with CTX and/or RT were not statistically different among patients with DM and without DM.

None of the patients had a laparoscopic procedure. A higher proportion of the patients with
DM had massive bleeding $(\mathrm{p}=0.027)$ and received blood transfusion $(\mathrm{p}=0.011)$ in comparison to patients without DM. Surgical procedure $(\mathrm{p}=0.034)$ as well as hospital stay $(p=0.028)$ was longer in patients with DM in comparison to those without $\mathrm{DM}$. None of patients died during the first month after a surgical procedure $(\mathrm{p}<0.0001)$. 


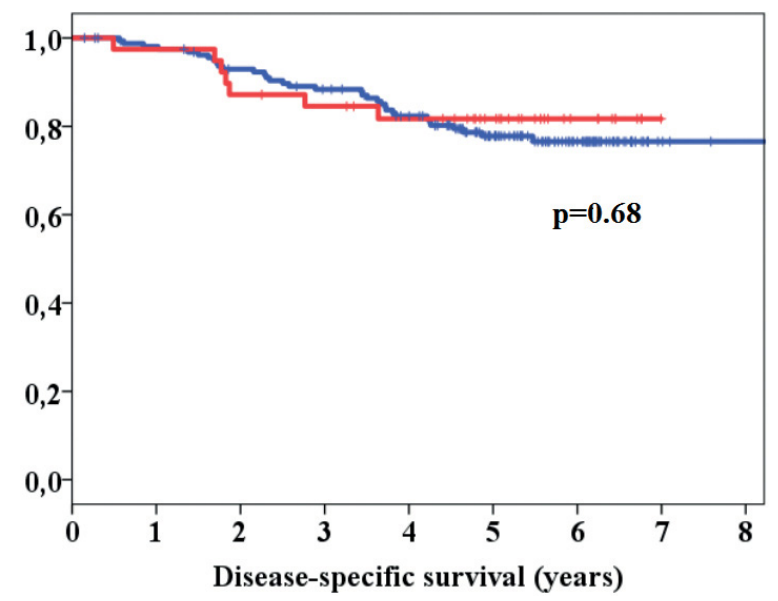

FIGURE 1. Cancer-specific survival of patients with and without Diabetes mellitus (DM).

red line = with DM; blue line $=$ without DM

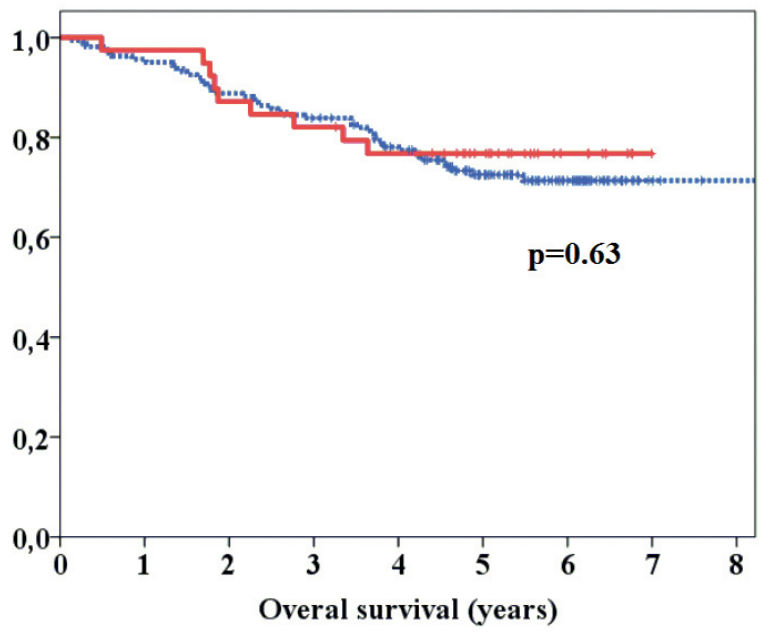

FIGURE 2. Overall survival of patients with and without Diabetes mellitus (DM).

red line = with DM; blue line $=$ without DM

The mean follow-up period was 4.75 years. Recurrence was diagnosed in $23 \%$ of patients with $\mathrm{DM}$ and in $25 \%$ of patients without DM ( $p=0.63)$. Locoregional recurrence was detected in 2/39 (5\%) patients with DM and in 11/161 (6.8\%) patients without DM. Distant metastases after surgical procedure were detected in 4 patients with DM and 33 patients without DM. Altogether, 41 patients died of cancer and 12 patients of other causes. Cause of death was not statistically different in patients with $\mathrm{DM}$ in comparison to those without DM ( $\mathrm{p}=0.74)$. Colorectal cancer was the cause of death in $18 \%$ and $21 \%$ of patients with and without DM, respectively. All causes mortality in patients with DM and without DM was $23 \%$ and $27 \%$, respectively.
Three-year cancer-specific survival (Figure 1) in patients with DM and without DM was $85 \%$ and $89 \%$, respectively $(\mathrm{p}=0.68)$. Three-year overall survival (Figure 2) in patients with DM and without DM was $82 \%$ and $84 \%$, respectively ( $p=0.63$ ). Patients with colon and rectal cancer had estimated median survival of 75 and 108 months ( $p=0.089$ ), respectively. All patients were included in our statistical analysis of survival because there was only small number of patients with low stage tumor, colon cancer and/or presence of DM which precluded adequate subgroup analysis.

\section{Discussion}

The aim of our study was to find out if DM in patients with advanced CRC was associated with cancer-specific and overall survival. In our 200 consecutive patients with elective surgical procedure for CRC, the presence of DM was not associated with cancer-specific or overall survival after the mean follow-up period of 4.75 years. Inversely, a metaanalysis of 26 observational studies on CRC has shown that patients with CRC and DM had a $17 \%$ increased risk of overall mortality and a $12 \%$ increased risk of cancer-specific mortality compared to those without DM. ${ }^{5}$ However, another metaanalysis has shown that persons with CRC and DM had a $32 \%$ increase in overall mortality compared to those without DM, but there were no associations between DM and risk of cancer-specific mortality. ${ }^{4}$ Bella et al. found that the presence of DM was significantly associated with decreased overall and cancer-specific survival. ${ }^{12}$ They analyzed 1,039 CRC cases who were included in a EUROCARE-5 high resolution study and were treated in Italy from 2003-2005. ${ }^{12}$ Their patients with and without DM did not differ in terms of type of resection, elective versus emergency surgery, or number of lymph nodes examined. Their patients with DM were older in comparison to the patients without DM. Furthermore, diabetics were significantly less likely to receive adjuvant therapy than nondiabetics. ${ }^{12}$ But our diabetics were not older than the non-diabetics $(p=0.13)$ and their overall and cancer-specific survival was not statistically different. A possible explanation is that the same proportion of patients from both groups had preoperative radiotherapy and/or chemotherapy, which might have influenced the survival of patients. Similarly to Bella et al. ${ }^{12}$, Van de Pol-Franse et al. ${ }^{13}$ also reported that patients with diabetes and CRC were treated less aggressively compared to those with- 
out diabetes. Another possible explanation for the differences in survival among the reported studies is a selection bias between population based and single institution based cohorts of patients. Our patients were treated at a single cancer comprehensive center, while Bella et al. report data from seven Italian cancer registries, and Van de Pol-Franse et al. report data from the registration area of the Eindhoven Cancer Registry. ${ }^{12,13}$ Both of them also included patients treated in general hospitals.

A substantial proportion of deaths in older persons with colorectal cancer can be attributed to chronic heart failure, diabetes mellitus, and chronic obstructive pulmonary disease. ${ }^{14}$ Polednak et al. ${ }^{15}$, in a population-based statewide Connecticut cancer registry, found that the presence of DM was associated with a statistically significantly elevated risk of death from any cause. This finding was due to an elevated risk of death from causes other than CRC. ${ }^{15}$ Similarly, Ota et al. ${ }^{16}$ reported, in 1.216 patients with CRC, that overall survival was significantly inferior in the patients with DM than in those without, but there was no difference in cancer-specific survival between the two groups. Nevertheless, cancer-specific survival was worse in diabetics in stage IV cancer, but it remained unclear whether this has been attributed to differences in malignancy or in treatment. ${ }^{16}$ On the other hand, Rao Kondapally Seshasai et al. ${ }^{17}$ found that DM was moderately associated with deaths from CRC cancer from individual-participant data on 123.205 deaths among 820.900 people in 97 prospective studies. DM worsens prognosis because it is frequently associated with comorbidities such as cardiovascular disease because they are associated with increased risk of death. ${ }^{12,18,19}$ Certain comorbidities such as heart problems, alcohol abuse, liver disease, and deep vein thrombosis had an impact on prognosis. ${ }^{20}$ Furthermore, the number of comorbid conditions was significant in predicting early mortality. ${ }^{20}$ Multimorbidity is common, and exerts a substantial effect on CRC survival. ${ }^{14}$ Therefore, comorbidity increases the complexity of cancer management and affects survival duration. ${ }^{20}$

Davila et al. ${ }^{21}$ studied 30-day mortality using National Veterans Administration administrative data, and found that patients who had received surgical resection more recently had a lower risk of 30-day mortality, compared with those resected in 1987-1988. Significant declines were observed in several postoperative disorders, including anesthesia complications and thromboembolism. ${ }^{21}$ Preoperative disorders associated with increased mortality included chronic pulmonary disease, congestive heart failure, diabetes, hemiplegia/ paraplegia, moderate/severe liver disease, and renal disease. ${ }^{21}$ Obviously, declining preoperative and postoperative disorders, as well as improvements in surgical care, could explain these findings. ${ }^{21}$ It is encouraging that none of our patients died during the first month after a surgical procedure. We believe that this reflects the high-quality postoperative care in our ICU and surgical wards. Similar observations were published by Jullumstro et al. ${ }^{22}$, who studied 1,194 patients treated for CRC at Levanger Hospital during a 25 year period. They found that the presence of DM was not associated with short-term survival or cancer specific survival. ${ }^{22}$ An important factor that might have contributed to the smoother postoperative course and low 30-day mortality in our center is our policy that all patients with malnutrition and/or cachexia had nutritional interventions and pharmacological therapy. ${ }^{23,24}$ It is well known that a low fat-free mass is associated with 28-day mortality after admission to the ICU. ${ }^{25}$ In our patients with DM, the illness marker and BMI were higher in comparison to those without DM. Furthermore, diabetics had a higher ASA score, which reflects a worse general condition and concomitant diseases. Our patients did not differ in tumor stage, but a higher proportion of patients with DM had massive bleeding and received blood transfusion in comparison to patients without DM. Therefore, it was not surprising that surgical procedure as well as hospital stay was longer in patients with DM in comparison to those without DM.

Jeon et al. ${ }^{26}$ observed that DM was significantly associated with worse overall survival and recurrence-free survival in colon cancer patients, while there was no association with the presence of DM and overall or disease-free survival in rectal cancer patients. This study in 4,131 patients with CRC suggests that DM negatively impacts survival outcomes of patients with colon cancer but not rectal cancer. ${ }^{26}$ Similarly, in colon cancer patients, Meyerhardt et al. ${ }^{27}$, in a large randomized adjuvant chemotherapy trial of 3,759 patients treated between 1988 and 1992, found that patients with DM experienced a significantly higher rate of overall mortality and cancer recurrence, and an increase in treatment-related diarrhea. Also Huang at al. ${ }^{28}$ reported that DM was a poor prognostic factor for overall and cancer-specific survival in 2,762 consecutive patients diagnosed with colon cancer in Taipei Veterans General Hospital. However, Shonka et al. ${ }^{29}$ found no significant relationship be- 
tween stage of colon cancer or survival and presence of DM in 1,853 patients with colon cancer treated in a single institution during an 18-year period. On the other hand, Bella et al. ${ }^{12}$ found that the presence of DM had a stronger adverse effect on rectal than colon cancer prognosis in 1,039 patients with CRC. Cancer-specific mortality was significantly higher among diabetics, while colon cancer-specific mortality was only non-significantly higher, even though overall mortality was significantly higher. ${ }^{12}$ In our patients with colon and rectum cancer, overall and cancer-specific survival was not statistically different, but the number of patients was too small to allow any reliable conclusions about possible differences in prognosis.

A limitation of this study is that it is retrospective, and the follow-up period is relatively short. Furthermore, there were only a small number of diabetics, which precluded analysis of the association between diabetes, stage of disease, location of cancer (rectum versus colon) and survival. Other limitations are the lack of information about diabetes type and age of diabetes onset, as well as the type and duration of diabetic therapy. Because of the relatively small number of diabetics, we could not analyze the association between different diabetic therapies (metformin and insulin) on outcome of patients. On the other hand, an advantage of our study is that a large proportion of patients had an advanced stage of disease with a higher risk of recurrence or progression of disease. All our patients were followed at our institution, so our data on recurrence and cause of death are very reliable.

\section{Conclusions}

The presence of DM was not associated with tumor stage, disease-specific survival or overall survival in a group of patients with advanced colorectal carcinoma treated at a cancer comprehensive center.

\section{Acknowledgements}

The paper was supported by a research program, P3-0289, by the Ministry of Higher Education, Science and Sport of Slovenia.

\section{References}

1. Berster JM, Göke B. Type 2 diabetes mellitus as risk factor for colorectal cancer. Arch Physiol Biochem 2008; 114: 84-98. doi: 10.1080/13813450802008455
2. Larsson SC, Orsini N, Wolk A. Diabetes mellitus and risk of colorectal cancer: a meta-analysis. J Natl Cancer Inst 2005; 22: 1679-87. doi: 10.1093/jnci/ dji375

3. González N, Prieto I, Del Puerto-Nevado L, Portal-Nuñez S, Ardura JA, Corton $\mathrm{M}$, et al. 2017 update on the relationship between diabetes and colorectal cancer: epidemiology, potential molecular mechanisms and therapeutic implications. Oncotarget 2017; 8: 18456-85. doi: 10.18632/oncotarget.14472

4. Stein KB, Snyder CF, Barone BB, Yeh HC, Peairs KS, Derr RL, et al. Colorectal cancer outcomes, recurrence, and complications in persons with and without diabetes mellitus: a systematic review and meta-analysis. Dig Dis Sci 2010; 7:1839-51. doi: 10.1007/s10620-009-0944-8

5. Mills KT, Bellows CF, Hoffman AE, Kelly TN, Gagliardi G. Diabetes mellitus and colorectal cancer prognosis: a meta-analysis. Dis Colon Rectum 2013; 11: 1304-19. doi: 10.1097/DCR.0b013e3182a479f9

6. Kerin Povsic M, Beovic B, Ihan A. Perioperative increase in neutrophil CD64 expression is an indicator for intra-abdominal infection after colorectal cancer surgery. Radiol Oncol 2016; 2: 211-20. doi: 10.1515/raon-2016-0016

7. Kerin Povsic M, Ihan A, Beovič B. Post-Operative Infection is an independent risk factor for worse long-term survival after colorectal cancer surgery. Surg Infect (Larchmt) 2016; 6: 700-12. doi: 10.1089/sur.2015.187

8. International Union Against Cancer (UICC). TNM classification of malignant tumors, 7th edition. Sobin LH, Gospodarowicz MK, Wittekind Ch, editors. New York: Willey; 2009.

9. Golo D, But-Hadzic J, Anderluh F, Brecelj E, Edhemovic I, Jeromen A, et al. Induction chemotherapy, chemoradiotherapy and consolidation chemotherapy in preoperative treatment of rectal cancer - long-term results of phase II OIGIT-01 Trial. Radiol Oncol 2018; 3: 267-74. doi: 10.2478/ raon-2018-0028

10. Fitz-Henry J. The ASA classification and perioperative risk. Ann R Coll Surg Engl 2011; 93: 185-7. doi: 10.1308/rcsann.2011.93.3.185a

11. Gupta D, Lis CG, Dahlk SL, King J, Vashi PG, Grutsck JF, et al. The relationship between bioelectrical impedance phase angle and subjective global assessment in advanced colorectal cancer. Nutr J 2008; 7: 19. doi: 10.1186/14752891-7-19

12. Bella F, Minicozzi P, Giacomin A, Crocetti E, Federico M, Ponz de Leon M, et al. Impact of diabetes on overall and cancer-specific mortality in colorectal cancer patients. J Cancer Res Clin Oncol 2013; 8: 1303-10. doi: 10.1007/ s00432-013-1439-8

13. Van de Poll-Franse LV, Houterman S, Janssen-Heijnen ML, Dercksen MW, Coebergh JW, Haak HR. Less aggressive treatment and worse overall survival in cancer patients with diabetes: a large population-based analysis. Int $J$ Cancer 2007; 9: 1986-92. doi: 10.1002/ijc.22532

14. Gross CP, Guo Z, McAvay GJ, Allore HG, Young M, Tinetti ME. Multimorbidity and survival in older persons with colorectal cancer. J Am Geriatr Soc 2006; 12: 1898-904. doi: 10.1111/j.1532-5415.2006.00973.x

15. Polednak AP. Comorbid diabetes mellitus and risk of death after diagnosis of colorectal cancer: a population-based study. Cancer Detect Prev 2006; 5: 466-72. doi: 10.1016/j.cdp.2006.07.003

16. Ota Y, Ishihara S, Otani K, Yasuda K, Nishikawa T, Tanaka T, et al. Effect of nutrient starvation on proliferation and cytokine secretion of peripheral blood lymphocytes. Mol Clin Oncol 2016; 4: 607-10. doi: 10.3892/mco.2016.763

17. Rao Kondapally Seshasai $S$, Kaptoge $S$, Thompson A, Di Angelantonio E, Gao P, Sarwar N, et al. Diabetes mellitus, fasting glucose, and risk of causespecific death. N Engl J Med 2011; 9: 829-41. doi: 10.1056/NEJMoa1008862

18. Woodward M, Zhang X, Barzi F, Pan W, Ueshima H, Rodgers A, et al. The effects of diabetes on the risks of major cardiovascular diseases and death in the Asia-Pacific region. Diabetes Care 2003; 26: 360-6. doi: 10.2337/ diacare.26.2.360

19. Booth GL, Kapral MK, Fung K, Tu JV. Relation between age and cardiovascular disease in men and women with diabetes compared with non-diabetic people: a population-based retrospective cohort study. Lancet 2006; 368: 29-36. doi: 10.1016/S0140-6736(06)68967-8

20. Yancik R, Wesley MN, Ries LA, Havlik RJ, Long S, Edwards BK, et al. Comorbidity and age as predictors of risk for early mortality of male and female colon carcinoma patients: a population-based study. Cancer 1998; 11: 2123-34. PMID: 9610691 
21. Davila JA, Rabeneck L, Berger DH, El-Serag HB. Postoperative 30-day mortality following surgical resection for colorectal cancer in veterans: changes in the right direction. Dig Dis Sci 2005; 9: 1722-8. doi: 10.1007/ s10620-005-2925-x

22. Jullumstrø $E$, Kollind $M$, Lydersen $S$, Edna TH. Diabetes mellitus and outcomes of colorectal cancer. Acta Oncol 2009; 3: 361-7. doi: $10.1080 / 02841860802637765$

23. Gorenc M, Kozjek NR, Strojan P. Malnutrition and cachexia in patients with head and neck cancer treated with (chemo)radiotherapy. Rep Pract Oncol Radiother 2015; 4: 249-58. doi: 10.1016/j.rpor.2015.03.001

24. Perpar A, Brecelj E, Kozjek NR, Anderluh F, Oblak I, Vidmar MS, Velenik V. Mesenteric ischemia after capecitabine treatment in rectal cancer and resultant short bowel syndrome is not an absolute contraindication for radical oncological treatment. Radiol Oncol 2015; 2: 181-4. doi: 10.2478/ raon-2014-0024

25. Thibault R, Makhlouf AM, Mulliez A, Cristina Gonzalez M, Kekstas G, Kozjek $N R$, et al. Fat-free mass at admission predicts 28-day mortality in intensive care unit patients: the international prospective observational study Phase Angle Project. Intensive Care Med 2016; 9: 1445-53. doi: 10.1007/s00134016-4468-3

26. Jeon JY, Jeong DH, Park MG, Lee JW, Chu SH, Park JH, et al. Impact of diabetes on oncologic outcome of colorectal cancer patients: colon vs. rectal cancer. PLoS One 2013; 2: e55196. doi: 10.1371/journal.pone.0055196

27. Meyerhardt JA, Catalano PJ, Haller DG, Mayer RJ, Macdonald JS, Benson AB 3rd, et al. Impact of diabetes mellitus on outcomes in patients with colon cancer. J Clin Oncol 2003; 3: 433-40. doi: 10.1200/JCO.2003.07.125

28. Huang YC, Lin JK, Chen WS, Lin TC, Yang SH, Jiang JK, et al. Diabetes mellitus negatively impacts survival of patients with colon cancer, particularly in stage II disease. J Cancer Res Clin Oncol 2011; 2: 211-20. doi: 10.1007/ s00432-010-0879-7

29. Shonka NA, Anderson JR, Panwalkar AW, Reed EC, Steen PD, Ganti AK. Effect of diabetes mellitus on the epidemiology and outcomes of colon cancer. Med Oncol 2006; 4: 515-9. doi: 10.1385/MO:23:4:515 